\title{
Imagens que valem mil palavras... A experiência do arquivo de memórias do Museu de São Brás ${ }^{1}$
}

\author{
Lorena Sancho Querol ${ }^{2}$ \\ Emanuel Sancho ${ }^{3}$
}

\begin{abstract}
Resumo
Nos países do sul da Europa as políticas de ajustamento socioeconómico que se vêm aplicando estão a traduzir-se num enfraquecimento progressivo da acção museal nas suas diversas formas. Questionados no âmbito dum processo de transformação que envolve uma profunda alteração dos modelos de gestão e dos valores vigentes, os museus procuram agora uma Museologia Sustentável.

Neste contexto emergem novas fórmulas museológicas que associam a sustentabilidade à criatividade social e à valorização da diversidade. Este é o caso do Museu do Trajo em São Brás de Alportel (MuT), no Algarve, e da sua "Museologia em camadas". Um modelo que assenta na gestão partilhada, tomando como ponto de partida o conhecimento profundo do território, a construção colectiva de sentidos
\end{abstract}

${ }^{1} \mathrm{O}$ presente artigo constitui um produto científico do projecto de pósdoutoramento da autora do texto. Sob o título "A Sociedade no Museu: estudo sobre participação cultural nos museus locais europeus" (SOMUS), este projecto conta com o apoio do Programa de Pós-doutoramento da Fundação para a Ciência e a Tecnologia, do Ministério da Educação português (2014-2016).

2Lorena Sancho Querol. Investigadora em pós-doutoramento, Centro de Estudos Sociais, Universidade de Coimbra.

3 Emanuel Sancho. Diretor do Museu do Trajo, São Brás de Alportel, Algarve. 
culturais, e a resignificação de saberes ancestrais com o objectivo de contribuir para um desenvolvimento equitativo.

Neste artigo apresentamos a estrutura, o método e os resultados de um dos seus projectos de referência: Fotografia, Memória e Identidade (FMId). Cruzando a investigação colaborativa com a cartografia de sentidos associados às fotografias de cada família, FMld baseia-se no exercício regular de uma arqueologia memorial que desemboca na descodificação de diversos segmentos da cultura local. As suas ressonâncias deixam marca nos restantes processos e funções museológicas, mas também em cada uma das famílias envolvidas no projecto, que agora possui uma conta corrente da memória no Museu da sua terra.

Palavras-chave: Museologia em camadas; fotografia; cartografias; participação.

\section{Abstract}

In the countries of southern Europe, the economic adjustment policies being applied are causing a progressive weakening of the museological action in its various forms. Questioned within the transformation process involving a profound change of the management models and of the prevailing values, museums seek a Sustainable Museology.

In this context, new museological formulas emerge associating sustainability to social creativity and to valorization of diversity. This is the case of the Costume Museum in São Brás de Alportel (MuT), in the Algarve, and its "Museology on layers". A model based on shared management, taking as its starting point a deep knowledge of the territory, the collective construction of senses and local cultural meanings, and the reframing of ancestral knowledge, with the objective of contributing to an equitable development.

In this paper we present the structure, the method and the results of one of the reference projects: Photography, memory and identity (FMId). In this case, a contrastive analysis between the collaborative research and the cartography of meanings associated with pictures of each family is performed. This exercise of memorial archaeology leads to decoding diverse segments of local culture. Its resonances reach every one of the museological functions and processes of MuT, but also each of the families involved in the project, have now a current account of memory in their hometown Museum.

Key-words: Museology on layers; photography; cartography; participation. 


\section{Introdução}

Cartografar as realidades socioculturais relacionadas com um território, uma temática ou um acontecimento, é hoje um gesto natural e necessário para qualquer museu que queira desenvolver as suas funções junto das comunidades e coletivos que com ele compartem um determinado território (Clark, Sutherland e Young, 1995).

Originalmente associada a tipologias museológicas específicas - como a dos museus etnológicos - pelo seu potencial de estudo das formas de organização e ocupação dos territórios, esta ferramenta é uma das chaves que conduz à construção de uma Museologia de cariz local, comprometida com a valorização da diversidade cultural, e com o desenvolvimento sustentável.

0 projeto que aqui apresentamos pertence precisamente a este tipo de Museologia, hoje em dia mais conhecida como Sociomuseologia. Trata-se de um museu local situado numa pequena vila do Algarve, cujo sentido e razão de ser são as pessoas: o Museu do Traje de São Brás de Alportel. A diferença radica em que não falamos só das pessoas na qualidade de público-visitante, mas também, e sobretudo, das pessoas como verdadeiras operárias da construção do processo museológico.

Neste contexto centramos a nossa atenção num dos projetos que aí se encontram em curso. Recebe o nome de Fotografia, Memória e Identidade, e consiste numa experiência que coloca a memória coletiva no centro do processo, reconhecendo-Ihe o seu poder de mediadora entre passado e presente (Reginaldo, no prelo). O ponto de partida são um conjunto de imagens perdidas no tempo e espalhadas pela Vila, imagens que, ao longo do processo se coletivizam e ganham voz, imagens que permitem cartografar a história da Vila em ponto pequeno e os processos de construção identitária em ponto maior (McLucas, s.d.). 
A final, o "Menu do dia" também é feito de lugares, pessoas, ingredientes ou ideias que viajaram no tempo até a nossa mesa.

\section{Um museu do mundo, numa escala local}

O projeto do Museu do Traje de São Brás de Alportel segue as linhas de atuação definidas pela Sociomuseologia, desenvolvendo a partir daí um modelo que, no essencial, é ditado pelas pessoas que interferem no seu processo quotidiano de construção. Herdeira da corrente museológica que conhecemos como Nova Museologia (desde 1972), e resultante da sua evolução e do reconhecimento da sua relação com outras ciências sociais a partir da década de 1990, a Sociomuseologia coloca como centro de gravidade do processo museológico a comunidade local. A partir dela centra a sua atuação na utilização de metodologias participativas que privilegiam o desenvolvimento integrado da pessoa e do território pela via da cultura ${ }^{4}$.

Num contexto desta natureza...

O museu é visto como um instrumento de democratização da cultura, que reconhece a relevância da diversidade local para o desenvolvimento integrado (Varine 2007: 23), e que por isso, age junto das pessoas para construir novas formas de equilíbrio. Tomando como ponto de partida ingredientes como a experiência social, o saber associado aos modos de habitar, ou os usos da natureza, este museu se propõe atingir objetivos relacionados com a inclusão social, a sustentabilidade nas suas múltiplas vertentes ou a educação não formal dos diversos segmentos da população local. Em suma, falamos de museus que agem

${ }^{4}$ Mais informação sobre os princípios e práticas da Sociomuseologia em: Sancho Querol, 2013: 167-178. 
com pessoas reais e problemas reais, em tempo real (Śola 2007: 38).

Sob esta perspetiva, o património é o resultado de um processo de identificação e seleção de realidades que, pela sua carga simbólica, e pelo seu poder de representação e de comunicação, refletem a evolução das nossas sociedades, das suas formas de vida, e dos valores culturais a elas associados. Assim, para além de ajudar-nos a perceber melhor a origem e evolução dos processos vitais de que somos parte, ou a definir os traços da nossa identidade social e cultural no tempo, a categoria património é uma ferramenta essencial para o desenvolvimento da consciência cultural e, consequentemente, para o desenho do presente. Em outras palavras, o património é uma categoria "boa para agir" (Gonçalves, no prelo).

Museu e património, são precisamente as duas peças centrais deste artigo, com algumas pequenas diferenças de forma e de fundo em relação aos usos sociais que deles se faz normalmente, que vêm definidas pelo caso de estudo que nos ocupa: um projeto de arqueologia memorial, que acontece num museu de cariz etnográfico, situado numa zona rural.

Assim, encontramo-nos com um museu local cujas origens se remontam ao ano de 1983, quando uma instituição de solidariedade social e cultural, a Santa Casa da Misericórdia, duma vila com 10.000 habitantes, São Brás de Alportel, se propôs criar um museu etnográfico para documentar a cultural local, com o objetivo de salvaguardar gestos próprios do território e das suas gentes, que se encontravam em rápida transformação. Desta forma, e como resultado de um longo caminho que se encontra documentado em trabalhos anteriores (ver Sancho Querol e Sancho, no prelo), surgiu o Museu do Trajo de São Brás de 
Alportel, denominado de forma abreviada MuT.

A partir daqui, o que torna diferente o MuT é o facto de ter criado, ao longo de todos estes anos, um método de trabalho próprio que assenta na definição de uma estrutura de camadas de ação social, cultural, ambiental e económica (Sancho Querol e Sancho, o.c.), a partir da qual se desenvolve a ação museológica com a comunidade.

Como resultado, o MuT tem hoje em curso projetos de educação patrimonial com as escolas locais, de dinamização de saberes locais em vias de desaparecimento com artesãos/ãs de diferentes proveniências e faixas etárias, de estudo de tradições ligadas à utilização dos recursos naturais do território, ou de inventário participativo dos modos de habitar o mundo rural junto das pequenas comunidades espalhadas pela serra.

Finalmente, no lugar do património encontramo-nos com um projeto que responde pelo nome de Fotografia, Memória e Identidade, ou FMId, que se propõe restituir à população, uma propriedade cultural coletiva como a memória (Varine 2007: 22), preservando a sua natureza criativa, e garantindo a sua presença e os seus usos contemporâneos, no âmbito mais alargado possível de proprietários/as y usuários/as (Sola 2007: 32) através do museu.

Com este objetivo, o FMId toma como ponto de partida as fotografias de família, isto é, imagens que, regra geral, não foram feitas com o propósito de documentar contextos sociológicos, etnográficos ou de alguma outra variante científica relacionada com o estudo da realidade humana. Outrossim, pelas suas características, espelham os mais diversos aspetos da vida quotidiana da vila ao longo do tempo, possuindo em comum o facto de terem sido validadas pelos seus proprietários e proprietárias para refletirem a imagem que desejam transmitir de si próprios/as. A partir deste universo visual, que nos liga ao mundo real, ganha vida 
um processo de interpretação da imagem junto de uma equipa de agentes locais, com quem foi possível cartografar a evolução da história e da identidade local com um nível de pormenor nunca sonhado.

\section{Arqueologias da memória: a fotografia como semente do diálogo no tempo}

"Las imágenes se hicieron al principio para evocar la apariencia de algo ausente. Gradualmente se fue comprendiendo que una imagen podía sobrevivir al objeto representado; por tanto podría mostrar el aspecto que había tenido algo o alguien, y por implicación como lo habían visto otras personas. Posteriormente se reconoció que la visión específica del hacedor de imágenes formaba parte también de lo registrado [...] Esto fue el resultado de una creciente consciencia de la individualidad, acompañada de una creciente conciencia de la historia." (Berger 2000: 16)

Criado em 2009 como um exercício de arqueologia memorial em torno do território do concelho de São Brás, o projeto FMId toma como ponto de partida um objeto memorial - a fotografia de família - para descodificar um amplo espectro de segmentos da cultura e da sociedade locais, até aqui desconhecidos pelo Museu e por grande parte da comunidade.

Esta ideia começou a ganhar voz quando se decidiu criar um espólio de memória visual local que juntasse as coleções fotográficas pessoais existentes na Vila e arredores, para as poder disponibilizar ao público por meio do Museu e das novas tecnologias.

Quer pela parte das pessoas que se disponibilizaram para partilhar a sua coleção pessoal de imagens, quer pela parte do Museu, sentiu-se desde o princípio a necessidade de superar a mera identificação formal da imagem com fins 
arquivísticos. Os anos e a reflexão resultante do trabalho em curso, trouxeram novas dimensões que permitiram perceber uma multiplicidade de aspetos relacionados com a identidade, a profissão, a relação entre as pessoas retratadas, a denominação e função associadas aos lugares, ou os acontecimentos e os saberes-fazer entretanto desaparecidos.

Foi assim que o Museu percebeu que, para além da recolha, documentação e disponibilização das imagens, o grande desígnio deste arquivo visual seria a democratização das memórias a elas associadas através de uma instituição como o museu, isto é, o desenvolvimento da sua responsabilidade social numa área tão estruturante como a da memória coletiva.

Sob esta perspetiva, o MuT passou a ser, a um mesmo tempo: o ponto de partida e a base de uma rede de habitantes locais que, percebendo a importância da iniciativa, contribuiria para a sua divulgação e para o envolvimento de novas famílias interessadas em participar; o depositário das memórias de cada família; o responsável pela recolha, organização e reutilização contemporânea do conhecimento que emerge com cada imagem descodificada. Desta forma, Museu e comunidade passaram a ser os principais beneficiários do exercício de memorização coletiva.

\subsection{O Grupo da Fotografia}

"A história de cada fotografia está ligada a um destino favorável ou não, e às interpretações a que for sujeita nos museus, arquivos, acervos particulares e caixas de recordações familiares." (Martins 2009: 297)

O grupo do FMId é um grupo aberto, dinâmico e com interesses diversos, que conta com uma equipa fiel de colaboradores/as, à qual, com frequência, se juntam novos/as participantes ou se retiram alguns dos que tinham aparecido 
temporariamente. Entre eles/as encontramos com pessoas que desejam partilhar as suas imagens, que pretendem contribuir para a identificação e documentação de imagens alheias, que simplesmente gostam de escutar e aprender com a experiência em curso, ou que procuram companhia para partilhar a nostalgia dos tempos da infância e juventude num ambiente construtivo. Em jogo está a descodificação das raízes e da evolução da sociedade sãobrasense ${ }_{\iota}$ mas também o desenvolvimento de uma outra consciência social e cultural essencial na construção do presente.

Neste sentido, o passar dos anos ajudou a construir uma sólida equipa, que atualmente está formada por um "núcleo duro" de 9-10 pessoas, comprometidas com a construção de um fundo memorial da localidade a longo prazo (ver Imagem 1). A este grupo fixo, cujas idades variam entre os 50 e os 85 anos, acresce por vezes uma ou outra pessoa que partilha estes interesses e esta causa, mas que, por motivos pessoais, não pode juntar-se ao grupo regularmente. Eles e elas constituem o Grupo da Fotografia, uma verdadeira equipa de Agentes de Memória local (Sancho Querol, no prelo) caracterizada pela diversidade de perfis, experiências e histórias de vida, e integrada por: João Pires da Cruz (expresidente da Câmara Municipal de São Brás de Alportel e estudioso autodidata da história local), Maria João Gaspar (ex-enfermeira ativa, voluntária e benemérita dedicada a casos sociais problemáticos), José Oliveira e Sousa (ex-militar interessado em história e património local), Luísa Pimenta e Maria João Caiado (duas costureiras com interesse na história local), Francisco Silva (corticeiro e ex-funcionário da Câmara Municipal), Amaro do Serro (ex-trabalhador corticeiro, e mais tarde proprietário de uma fábrica de cortiça, interessado nas memórias da terra), Inélida Gonçalves (cozinheira interessada em memórias de acontecimentos locais e construção de genealogias), Manuel Vargas (ex-camionista, e mais tarde empresário de camionagem, da industria corticeira). 


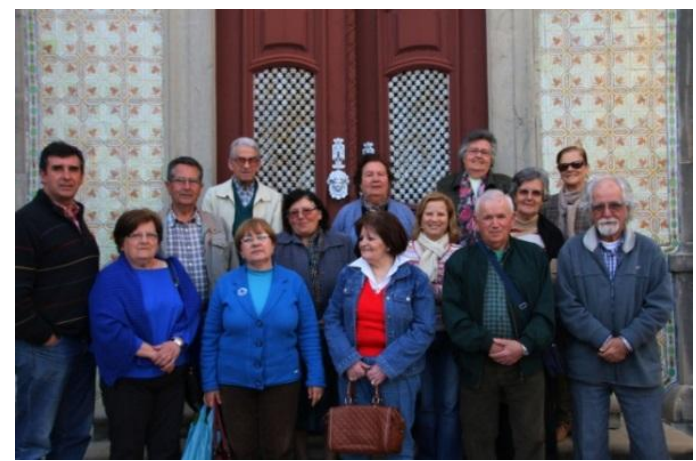

Imagem 1: O Grupo da Fotografia (Abril 2014)

Fonte: Arquivo do $\mathrm{MuT}^{5}$

Simultaneamente, o Grupo da Fotografia acaba por ser o elo de ligação do Museu à comunidade, pois não só forma parte dela, como goza da credibilidade e do respeito de cada uma das partes envolvidas no processo de construção deste Arquivo.

Neste contexto, e em resposta as linhas de atuação do MuT, importa referir que o Grupo assumiu-se desde um princípio, não só como recoletor dos documentos junto da população local, mas também como força motriz de um projeto que representa, quer para eles e elas, quer para a comunidade sãobrasense, a transmissão de um legado próprio, essencial para perceber outras dimensões da história e da identidade da Vila.

\subsection{A metodologia}

"Dezenho obtido pela luz, ou processo segundo o qual os objetos por si mesmos se dezenhão sem socorro de lapiz" (retirado de uma das primeiras noticias publicadas em

\footnotetext{
${ }^{5}$ A totalidade das imagens utilizadas neste artigo formam parte do Arquivo do MuT.
} 
Portugal, para dar a conhecer as descobertas de Daguerre e Talbot. Revista Litteraria, Porto, março de 1839, in Sena 1998: 16)

O projeto FMId assenta a sua atuação na utilização de metodologias participativas que envolvem a comunidade em cada um dos passos que dão vida ao processo. Inspirado nas ideias de Bourdieu (1965) e Barthes (1980) sobre aquela que nos parece ser uma "sociologia informal da fotografia", FMId cruza a investigação colaborativa com a cartografia de sentidos associados às fotografias de cada família. A partir de aqui seu modus operandi baseia-se no exercício e partilha regular das memórias submersas no tempo e resgatadas no âmbito de uma atividade coletiva que acontece uma vez por semana no Museu.

Assim, desde há 6 anos, todas as quintas feiras, as 15 horas, tem início a sessão de trabalho do Grupo da Fotografia, com participação de pelo menos um representante do MuT. Esta sessão tem uma duração aproximada de 3 horas, ao longo das quais segue-se uma ordem previamente definida pela tipologia e conteúdos dos espólios fotográficos que aguardam a sua vez de ganhar voz, ou então pelas temáticas que a equipa quere desenvolver em profundidade, para completar as pesquisas em curso. Neste contexto, o Museu assume o papel de mediador, ajudando a orquestrar o processo de pesquisa, e responsabilizando-se pela guarda e utilização contemporânea da informação que emerge em cada sessão de trabalho.

Com este objetivo, a equipa do MuT criou e mantem uma base de dados em formato digital, que já incorporou cerca de 37.000 imagens representativas de 400 famílias do Concelho e limítrofes, e também documentação gráfica e audiovisual associada às imagens. Esta base abarca todos os períodos, lugares e segmentos sociais do território, organizados segundo 5 categorias, que vão sendo afinadas 
conforme o espólio aumenta e se diversifica, e que foram pensadas a partir de uma pequena seleção de ideias e conceitos procedentes das áreas da Etnografia (Martins 2009: 312-314) e dos Estudos do Património (UNESCO 2003 e 2005).

Assim, e tendo em atenção os temas de interesse num âmbito como o da memória local da comunidade, surgiram as cinco categorias ou campos temáticos que integram o arquivo, organizadas, pela sua vez, em subcategorias que seguem o critério alfabético, e que emergem a partir das imagens cartografadas.

Sob esta perspetiva, convém dizer que o critério originalmente utilizado na definição do número de inventário, de caracter sequencial atendendo à ordem de entrada do objeto, foi substituído por aquele que fazia verdadeiro sentido para o Grupo, isto é, segundo as unidades familiares que habitam o território.

Relativamente à dimensão material do objeto em estudo, quer seja ele fotografia, documento ou registo de outra natureza, o método utilizado no projeto prevê o empréstimo para efeitos de digitalização, seguido da devolução à respetiva família uns dias depois. Esta opção, que reconhece a dimensão sociocultural do objeto, assenta as suas bases nas teorias de autores como Crimp (1995, in Martins 2009: 299), para quem a fotografia perde a sua capacidade informativa quando é afastada do mundo ao qual pertence, e também nos princípios da Sociomuseologia. Desta forma, o Museu considera prioritária a "posse afetiva" dos objetos por parte de cada família, em detrimento da "posse efetiva" dos originais no arquivo da instituição.

Por este motivo, o arquivo visual do FMld é maioritariamente composto por ficheiros digitais, estando apenas uma pequena percentagem de originais (aproximadamente 3\% do total) arquivadas no Museu, pelo facto de proceder do seu arquivo antigo, ou porque, devido a 
situações especiais (processos legais, emigração, falecimento...), as pessoas optaram por doar os seus espólios ao Museu.

Como resultado o arquivo encontra-se organizado nas cinco categorias que a seguir mostramos:

\section{Categoria 1 - PESSOAS}

Cultura popular: vestuário (trabalho e solene), indumentária tradicional, modas e contextos locais, ostentação, relações de poder.

Fenómenos sociais: emigração, festas, rituais, cerimónias (casamentos, manifestações religiosas, funerais, bailes). Instrução e Educação: escolas, vida escolar, valores e princípios.

Personalidades locais: poetas, políticos/as, empresários/as.

Religiosidade: vida e morte, pagelas religiosas, manifestações do quotidiano, terminologia, simbologia.

Sociedade local: estudos sociológicos, estudos genealógicos, demografia, relações de vizinhança, parentesco, alterações sociais, registo de alcunhas e suas origens.

\section{Categoria 2 - LUGARES}

Evolução urbana e do território: estudos geográficos, toponímia local extinta (oficial e não oficial), lugares, sítios, ruas.

Monumentos locais e edifícios notáveis: alterações, restauros, transformações, arquitetura religiosa.

\section{Categoria 3 - INSTITUIÇÕES}

Associações, clubes e organizações: hierarquias, organização, valores, evolução.

Mundo militar: história, poder, fardas, armas.

\section{Categoria 4 - ARTES E OFÍcIOS}

Arte: artistas, espólios de diversa natureza (gravura, caricatura...) 
Fotografia: fotógrafos/as, técnicas, evolução da fotografia, amadores/as, fotógrafos/as viajantes, espólios fotográficos.

Profissões: profissões tradicionais (desaparecidas e em transformação), artesanato, utilização de recursos naturais locais.

\section{Categoria 5 - DOCUMENTOS}

Documentos relevantes (associados a imagens): certidões e cédulas profissionais, correspondências, arquivo (público e privado), economia e finanças, depoimentos áudio/vídeo, registos de vida local.

Papéis volantes: folhetos, anúncios, quermesses, cartazes

\subsection{Os objetivos}

"Na medida em que os patrimônios encontram "ressonância" no corpo e na alma dos homens e mulheres que pretendem representar, opera-se um trabalho subjetivo de reconstrução do patrimônio, no qual a dimensão individual ou da personalidade individual é incontornável. Nesse sentido, a ressonância pode ser entendida como mais que a simples "... [evocação] no expectador das forças culturais complexas e dinâmicas de onde eles emergiram". Na verdade trata-se de um trabalho permanente, interminável de reconstrução subjetiva. (Gonçalves, no prelo).

Neste contexto, ao longo do processo de construção do arquivo foram sendo definidos alguns objetivos que refletem o espirito da equipa e do projeto, e também a relação de reciprocidade que se foi consolidando entre Museu e Comunidade, através de um território como o da memória e de um objeto musealizável como a fotografia. De entre eles gostaríamos de destacar os seguintes: 
a) Trabalhar as memórias visuais do território a partir dos arquivos de fotografia das famílias do concelho, visando a construção de um imenso álbum da comunidade capaz de descodificar cartografias sociais, culturais, rurais, e urbanas, há muito tempo esquecidas, e fundamentais para a compreensão e a construção do presente.

b) Criar um corpus de conhecimento sobre a Vila e as suas gentes, diretamente proporcional ao nível de participação da população local.

c) Construir o processo museológico de forma sustentada e participativa, visando o reconhecimento da diversidade sociocultural que caracteriza a comunidade e, simultaneamente, a criação de um acervo sobre a sua história e identidade.

d) Encontrar o caminho certo para trazer as pessoas mais simples da comunidade (camponeses/as, pessoas com um nível baixo de escolaridade, donas de casa, ...) até ao Museu, criando com elas uma relação de cumplicidade, onde o Museu adquire um outro estatuto, passando a formar parte do "círculo de amigos".

\subsection{As Reciprocidades: a devolução à comunidade como chave do processo museológico}

"MUSEUMS WORK IN CLOSE COLLABORATION WITH THE COMMUNITIES FROM WHICH THEIR COLLECTIONS ORIGINATE AS WELL AS THOSE THEY SERVE [...]

Museum collections reflect the cultural and natural heritage of the communities from which they have been derived. As such, they have a character beyond that of ordinary property, which may include strong affinities with national, regional, local, ethnic, religious or political identity..." (ICOM Code of Ethics for Museums, 2013, 6응 Article) 
O MuT é um projeto museológico coletivo cuja razão de ser são as pessoas, mas também o processo de transformação da sociedade e da natureza que elas conduzem, e que desemboca num conjunto de sentidos e significados aos quais chamamos cultura (a partir de Lord 2014).

Assim, o projeto do MuT estrutura-se a partir de uma ideologia que coloca em primeiro lugar a utilidade do museu para o desenvolvimento das pessoas e do território, sendo por isso essencial que, a cada passo, a comunidade seja parte ativa do processo museológico.

Sob esta perspetiva, o projeto FMId integra uma estrutura onde, como vimos (ponto 2), existem diferentes níveis de interação social, cultural, económica e ecológica em curso, que não só enriquecem o projeto museológico como constituem um lugar de expressão, reconhecimento e emancipação da comunidade a vários níveis.

Neste contexto, FMId constitui um caso de sucesso pela sua maneira de construir o caminho junto da comunidade local, precisamente porque conseguiu estabelecer um equilíbrio de sentidos que ambas as partes reconhecem como essencial para o andamento dos seus percursos de vida. Nele podemos identificar os elementos clássicos de um processo de comunicação que, neste caso, se desenvolve em torno de uma peça chave para a construção do Museu e da sociedade: a nossa memória.

Desta forma, na qualidade de emissor encontramos o Grupo que, com o tempo e o andamento natural do processo, foi-se transformando no motor da relação entre Museu e comunidade.

$\mathrm{Na}$ qualidade de recetor está o Museu que escuta, questiona, regista e, posteriormente, devolve à comunidade de duas formas: uma, em forma de exposições, atividades, publicações..., outra, com a regularidade das quintas-feiras dos últimos 6 anos, na forma de processo regular de 
construção coletiva de sentidos e significados, onde a comunidade tem a voz principal, e que se traduz num processo de construção identitária forte e seguro.

$\mathrm{Na}$ qualidade de objeto que justifica o processo de comunicação encontramos a fotografia, surgindo a partir dela uma multiplicidade de mensagens que nos poem em contacto com um universo de memórias locais. Desta forma, a fotografia assume plenamente o seu papel de veículo da herança cultural e territorial da Vila de São Brás.

No entanto, este processo de comunicação apresenta algumas especificidades interessantes que nos permitem perceber melhor a ideia de reciprocidade museológica. Entre elas podemos destacar o facto de que:

-cada emissor é também recetor, pois recebe o conhecimento coletivo associado a uma determinada imagem;

-o recetor é também emissor numa vertente multimodal;

-o objeto de estudo que justifica o processo de comunicação é explorado na sua dupla dimensão material e imaterial, o que coloca a fotografia (objeto) como manancial de memória (imaterial) e, consequentemente, como via de reconhecimento da diversidade cultural (UNESCO 2001), da experiencia social local (Santos 2009), e da própria pessoa, através das suas histórias de vida, e do "saber como foi" que se traduzem no reconhecimento (autoestima).

É por isso que Museu e comunidade confluem na ideia de terem conseguido criar, ao longo destes anos, uma "conta corrente da memória" para cada uma das famílias locais. (Cf.: www.museu-sbras.com/grupo-fotos.html).

\subsection{Quatro exemplos sobre as cartografias coletivas} da 5a feira

Muitos são já os percursos visuais que foram explorados ao longo dos últimos anos no âmbito do FMId. Sob esta perspetiva e para mostrar alguns exemplos que 
permitam perceber o tipo de trabalho que esta em curso, e as práticas cartográficas em contexto de grupo, escolhemos quatro imagens que ilustram as categorias temáticas do arquivo, e apresentamo-las comentadas junto de alguns dos documentos que lhes estão associados. O objetivo é mostrar a interligação de registos, temáticas e categorias que formam parte da própria vida das coisas, mas também o poder estruturante da memória na construção da história e da identidade de uma pequena Vila.

No campo da cultura, estas relações descobrem-se com o tempo e como resultado de um trabalho regular e constante, até porque a comunidade tem vida própria e o Museu é só um dos seus desafios semanais.

Categorias 1, 3 e 5: Pessoas, Instituições e Documentos.

Subcategorias: Fenómenos sociais (1); Associações, clubes e organizações (3); Papeis volantes (5)

Estudo sociológico de organizações culturais locais, como é o caso do grupo de teatro existente em São Brás de Alportel na década de 20 do século XX, a partir de uma imagem onde se apresenta a equipa completa deste coletivo, segurando um deles o folheto de divulgação da peça em representação.

\section{Descobertas durante o processo cartográfico:}

A primeira imagem ( 2 e 3 ) permitiu identificar as pessoas e, com elas, as classes sociais representadas no universo do teatro, as relações de parentesco, as formas de organização social, as atividades profissionais do grupo, e também diversas questões relacionadas com género, hábitos culturais ou religiosos. A segunda imagem (4) surgiu depois de uma pesquisa aprofundada sobre o grupo, que inicialmente tinha sido identificado como o elenco da revista "Armando aos pássaros" (1928), revelando-se 
posteriormente, com base na análise detalhada do papel que um dos membros segura na zona do joelho, como o elenco de uma outra peça teatral, em nada relacionada com a primeira.

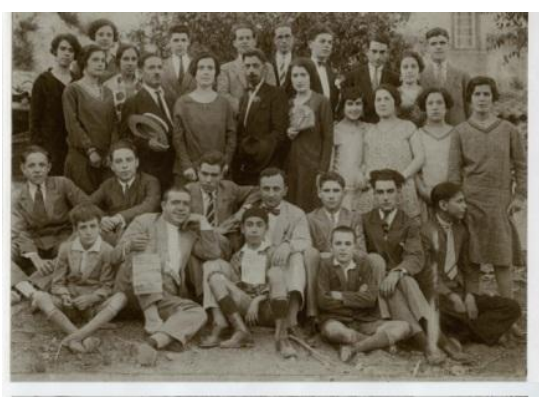

Imagem 2: Elenco da peça teatral "De Volta a Parvonilândia" (1929) (inv. sbv 2056)

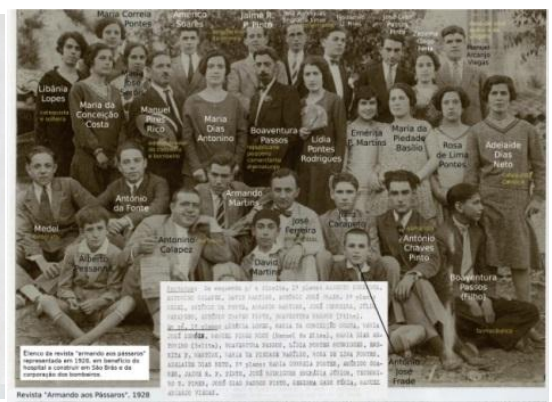

Imagem 3: Cartografia social do grupo (inv.sbv 2056i)

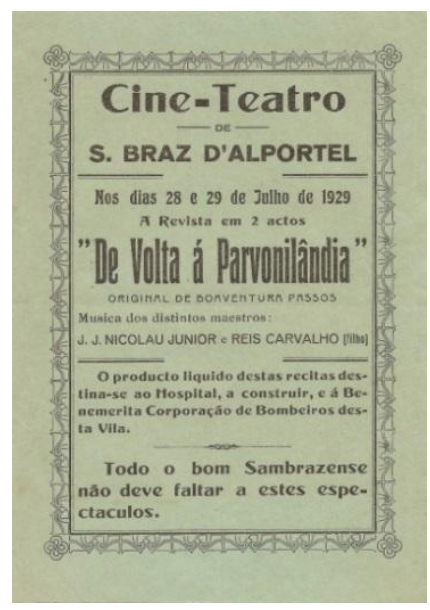

Imagem 4: Folheto original de divulgação da peça de teatro (inv. sba 1139doc) 
Categorias 2 e 5: Lugares e Documentos.

Subcategorias: Evolução urbana e do território (2); Documentos relevantes (5).

Estudo da evolução urbana da Vila de São Brás, nomeadamente do Largo de São Sebastião (Largo Central da Vila), a partir do qual se desenvolveu a vida da localidade desde as suas origens. $O$ ponto de partida foram dois postais, datados de 1932 (imag. 5) e de 1940 (imag. 6), assim como duas plantas da Vila, de 1912 (imag. 7) e de 1925 (imag. 8). Os quatro elementos iniciais, cuja identidade e relação foi identificada ao longo do trabalho, permitiram perceber o processo de evolução da Vila e de alargamento e modernização do seu centro de vida social e comercial em meados do sec. XX. Permitiram igualmente conhecer a evolução da toponímia local, na sua dupla vertente: oficial e não oficial.

O extremo dinamismo daquele espaço urbano ficou comprovado pela sucessão das tipologias de ocupação que foi possível identificar num espaço de tempo relativamente reduzido (cerca de 40 anos) e num espaço geográfico igualmente muito limitado (cerca de $500 \mathrm{~m}^{2}$ ). Assim, foi possível identificar as identidades dos/as habitantes, as sequências de ocupação dos espaços, as dinâmicas comerciais (negócios que surgiram e que se extinguiram dando lugar a outros), até descobrir que neste aglomerado tinha existido uma prisão.

\section{Descobertas durante o processo cartográfico:}

Percebeu-se assim que a evolução urbanística de São Brás parte de um elemento central: a igreja matriz (de final séc. XV), e que a sua ligação à uma pequena ermida construída nos arrabaldes da localidade em pleno séc. XVII (1673) e dedicada a São Sebastião, daria lugar à via nobre da terra: a antiga Rua de São Sebastião, e atual Rua Gago Coutinho. Posteriormente, e devido ao comércio da cortiça (uma das mais importantes fontes de economia local a partir 
de meados do sec. XIX), a aldeia começaria a desenvolver-se em torno do Largo, considerado a partir de ai o espaço de modernidade da Vila. Nele se concentrariam estabelecimentos comerciais (mercearia, barbearia), dependências municipais (cadeia, matadouro) e também residências de famílias locais abastadas.

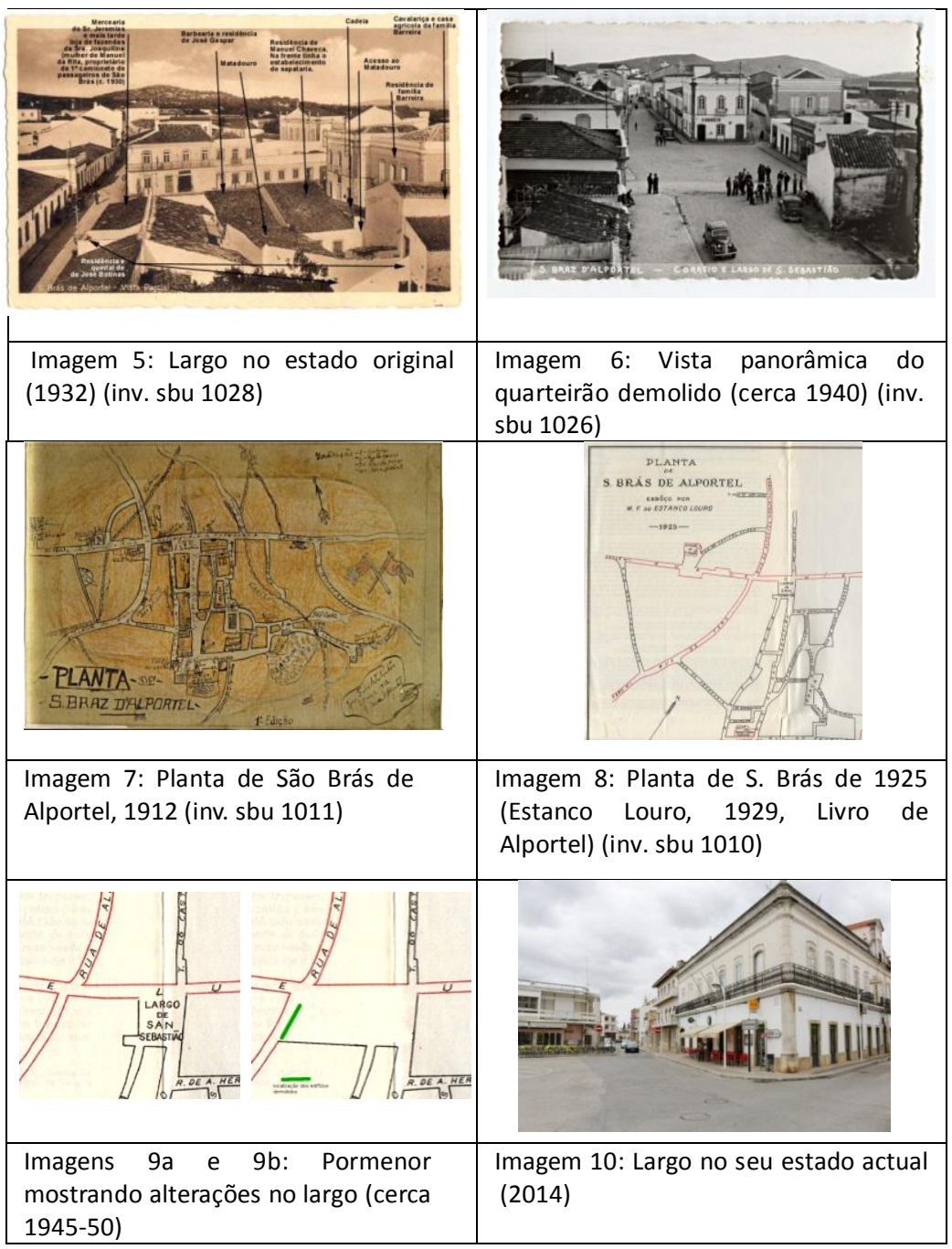


Com o passar do tempo, e em resposta a imagem e modernidade pretendida pelos/as habitantes, a velha ermida seria destruída e o Largo ampliado, sendo eliminadas varias residências privadas, a barbearia, a mercearia, a cadeia e o matadouro (imag. 6, 9a e 9b).

Categorias 3 e 5: Instituições e Documentos

Subcategorias: Associações, clubes e organizações (3); Documentos relevantes (5).

Estudo da origem e evolução da Associação Humanitária dos Bombeiros Voluntários de São Brás de Alportel, desde os seus inícios - em 1927 - até a atualidade, a partir de uma imagem do seu corpo de bombeiros voluntários (11).

Em meios pequenos como é o caso da Vila de São Brás, é motivo de orgulho pertencer ao corpo de bombeiros pois a população local reconhece-lhes toda uma responsabilidade social que se traduz num estatuto de destaque. Assim, os bombeiros estavam sempre presentes nas cerimónias oficiais, tinham a sua própria banda musical, e inclusive, podiam receber dádivas de beneméritos ricos que, por vezes, os nomeavam herdeiros.

\section{Descobertas durante o processo cartográfico:}

Nesta imagem aparece um dos fundadores da Associação, Manuel Pires Rico, e também um dos primeiros bombeiros, Custódio Raimundo Caco (12 e 13). Originalmente denominada Associação Humanitária dos Bombeiros Voluntários de Alportel, esta associação é o resultado de uma vontade coletiva, motivada pelo incêndio de uma fábrica de cortiça local no ano 1927, e coordenada por Pires Rico (1으 comandante do corpo de Bombeiros) e pelo médico da Vila, Dr. Alberto de Sousa, entre outros.

Ao longo da sua intensa história a Associação seria legalizada (em 1930), conseguiria uma sede própria (em 
1985) e alteraria os seus estatutos passando a designar-se, a partir de 1993, Associação Humanitária dos Bombeiros Voluntários de São Brás de Alportel (Sousa Chaveca 2005: 46201).

No grande incêndio que dizimou a serra de São Brás no verão de 2012 esta associação, apesar da sua limitada capacidade operativa, teve um papel fundamental na orientação dos processos e, sobretudo, na logística relacionada com a gestão do salvamento e do acolhimento.

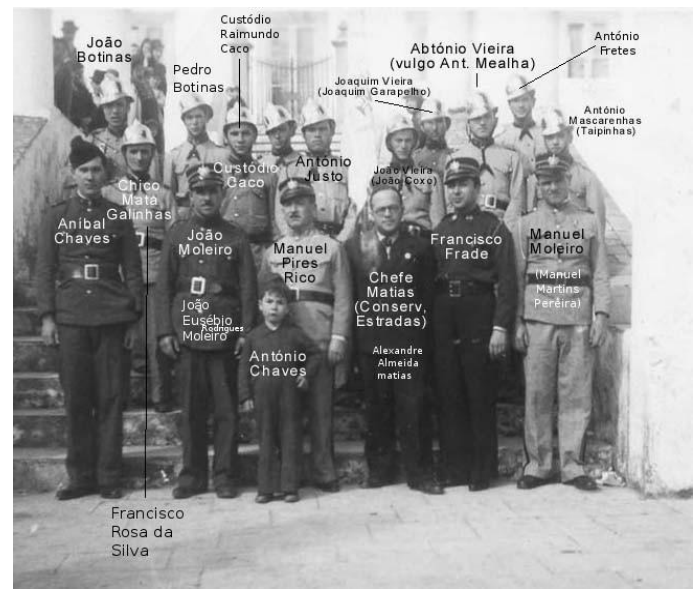

Imagem 11: Grupo de bombeiros voluntários de São Brás de Alportel (1939). Jardim da Verbena (antigo Jardim do Paço Episcopal) (inv. sbb 1004i)

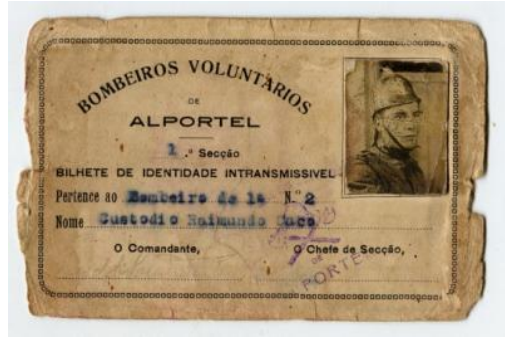

Imagem 12: Cartão de bombeiro voluntário de Custódio Caco, frente (1944) (inv. cac 1006)

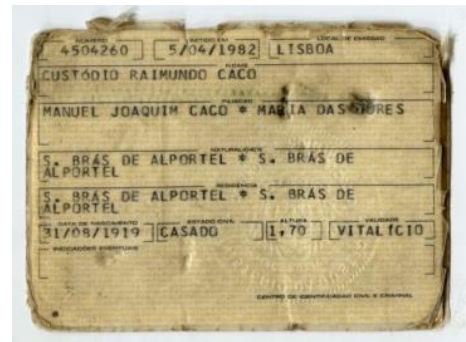

Imagem 13: Último Bilhete de Identidade de Custódio Caco, verso (1982) (inv. cac 1001) 
Categoria 4: Artes e ofícios

Subcategoria: Profissões

Estudo de profissão tradicional desaparecida na década de 1990 no barrocal do Algarve, e vulgarmente conhecida como "a mulher das vassouras". O ponto de partida foi o retrato de uma artesã do ramo (imag. 14).

\section{Descobertas durante o processo cartográfico:}

A fabricante de vassouras chama-se Almerinda Correia, e é uma habitante que mora atualmente no sítio da Soalheira, em São Brás de Alportel. Almerinda iniciou o fabrico de vassouras artesanais a base de palmeira anã (espécie arbórea própria do Mediterrâneo, de nome científico Chamaerops Humilis L) em 1951, e manteve essa atividade até 1993. Na década de 80 , com a atividade em plena decadência devido a concorrência dos produtos industriais, Almerinda logrou prolongar o fabrico artesanal de vassouras aproveitando os apoios destinados ao incentivo do artesanato local (imag. 15).

Desta forma, assistiu assim a uma mudança de funções e sentidos do objeto que ela sabia fabricar, abandonando a sua utilidade para transformar-se num produto turístico.

O desaparecimento de saberes-fazer tradicionais, a sua evolução com fins puramente decorativos, ou a sua renovação no âmbito das formas de vida atuais, tem sido tema de intenso debate no Museu. Neste contexto, o MuT encontra-se envolvido em projetos como o TASA: Técnicas Ancestrais, Soluções Atuais $^{6}$, centrados no estudo e reutilização contemporâneos dos saberes tradicionais locais.

\footnotetext{
6 Mais informação sobre o projeto TASA em: http://www.projectotasa.com/produtos/vassourinha/ http://www.projectotasa.com/artesaos/da-torre/
} 


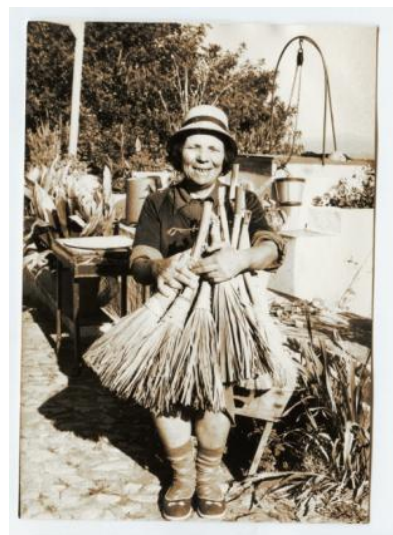

Imagem 14: Almerinda Correia com as suas vassouras artesanais (1981) (inv. etn 1012)

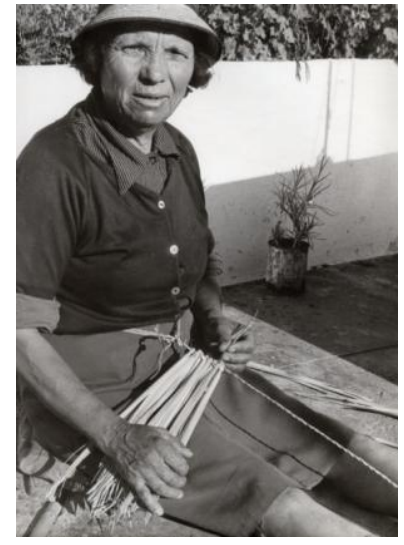

Imagem 15: A artesã explicando o processo de fabricação da vassoura (inv. etn 1039)

\section{Reflexão final}

Como em todo caminhar coletivo, ao longo destes seis anos de trabalho ouve altos e baixos, momentos de desorientação, sentidos a desvanecer e sentidos a emergir. A memória não é um património fácil, tem zonas de luz e zonas de sombra, tem um fiel companheiro, o esquecimento, e uma boa aliada, a partilha. Mas, acima de tudo, é um manancial inesgotável de conhecimento e compreensão das nossas sociedades, quando utilizado no plural.

A experiência de tradução cultural (Santos 2004: 157197) operada pela equipa do FMId ao longo dos últimos anos, permitiu descobrir novas dimensões do processo participativo, que contribuem para o alargamento da função social do museu no seio das sociedades contemporâneas.

Entre elas, podemos destacar, por exemplo, a definição sólida e pormenorizada das identidades ao longo do tempo; a valorização da diversidade e das especificidades culturais locais; o resgate, a resignificação e a dinamização de saberes esquecidos no tempo como consequência do seu 
esvaziamento funcional, ou o conhecimento aprofundado dos processos de transformação dos espaços públicos da vila.

Subjacente a todas elas, encontramos um processo museológico que, ao inverter os papéis, permitiu desenvolver um modelo de trabalho que coloca no centro do processo pessoas dos mais diversos perfis e experiencias de vida, um modelo que privilegia a alteridade, o respeito e o diálogo intergeracional.

Da mesma forma, o museu tornou-se numa plataforma de emancipação cultural, ou seja, num lugar acessível, onde agora entram com frequência outras pessoas da comunidade, que antes não tinham hábitos culturais relacionados com este mundo (museus, património, identidade...). Elas ajudaram a construir outras caras da história, até aqui desconhecidas, e a perceber a evolução dos processos que desembocam no São Brás atual. Elas tornaram-se defensoras das suas tradições e guardiãs de um dos mais importantes patrimónios de que são detentoras: a memória.

Cada quinta feria, o Grupo da Fotografia cartografa sentidos, saberes, pessoas... cartografa-se a si mesmo, cartografa mundos silenciados pelo tempo.

É por isso que o "Menu do Museu" não tem lugares reservados nem dispensa gente com memória fresca e conversas quentes. O comentário mordaz e a gargalhada franca vão bem com o chá de Bela-luísa e os biscoitos de alfarroba. 


\section{Referências}

-Barthes, R. (1980), A Câmara Clara. Lisboa: Edições 70. -Berger, J. (2000), Modos de ver. Barcelona: Gustavo Gili SA. -Bourdieu, P. (1965), "La définition sociale de la photographie", in Pierre Bourdieu (Org.), Un art Moyen essai sur les usages sociaux de la photographie. Paris: Les Éditions de Minuit/ "Le Sens Commun", 108-138.

-Clark, I.; Sutherland, J.; Young, G. (1995), Mapping Culture - A Guide for Cultural and Economic Development in Communities. AGPS: Canberra.

-Gonçalves, J. R. S. (no prelo), "Patrimônio e Cultura Subjetiva", e-cadernos CES, número temático subordinado ao tema "Dez anos da Convenção do Património Imaterial: ressonâncias norte-sul".

-ICOM (2013), ICOM Code of Ethics for Museums.

-Lord, G; Lord, B. (2010). "What is culture?", in Gail Lord; Barry Lord. Artists, Patrons, and the Public: Why Culture Changes. United Kingdom: AltaMira Press, 9-16

-McLucas, Clifford (s.d.), "There are ten things that I can say about these deep maps". Disponivel em: http://documents.stanford.edu/MichaelShanks/51

-Martins, L. (2009), "A fotografia de Rocha Peixoto. Reflexões em torno do seu lugar num projeto etnográfico", Boletim Cultural da Póvoa de Varzim, vol. 43, 297-314.

-Sancho Querol, L. (2013): "Para uma gramática museológica do (re)conhecimento: ideias e conceitos em torno do inventário participado", Sociologia, Revista da Faculdade de Letras da Universidade do Porto, vol. XXV, 165188. Disponível em: http://ler.letras.up.pt/uploads /ficheiros/11484.pdf

-Sancho Querol, L. (no prelo), “Museos polifónicos, memorias cotidianas y esencias urbanas" in Atas do 7음 congreso CEISAL: "Memoria, Presente y Futuro en América Latina". Porto: CEISAL, Universidade Fernando Pessoa e Núcleo 
de Estudos Latino- Americanos.

-Sancho Querol, L.; Sancho, E. (no prelo), "Sujeitos do património: os novos horizontes da Museologia Social em São Brás de Alportel", e-cadernos CES, número temático subordinado ao tema "Dez anos da Convenção do Património Imaterial: ressonâncias norte-sul".

-Santos, B. de Sousa (2004), "A Critique of Lazy Reason: Against the Waste of Experience", in Immanuel Wallerstein (Org.), The Modern World-System in the Longue Durée. Boulder: Paradigm Publishers, 157-197.

-Santos, B. de Sousa (2009), "Para além do pensamento abissal: das linhas globais a uma Ecologia de Saberes" in Boaventura de Sousa Santos; Mạ Paula Menezes (Orgs.), Epistemologias do Sul, CES, Coimbra: Almedina, 23-71.

-Sena, A. (1998), História da imagem fotográfica em Portugal. 1839-1997. Porto: Porto Editora.

-Śola, T. (2007), “¿Será el museo capaz de defenderse? Una mirada sobre la inspiración del Ecomuseo", mus- $A$ nㅇ 8, Dirección General de Museos, Consejería de Cultura, Junta de Andalucía, 30-39.

-Sousa Chaveca, S. (2005), Memórias do Povo Sambrasense. Oliveira de Azeméis: Edição de autor.

-UNESCO (2003), Convention for the Safeguarding of Intangible Cultural Heritage.

-UNESCO (2005), Convention on the Protection and Promotion of the Diversity of Cultural Expressions.

-Varine H. (2007), "El Ecomuseo. Una palabra, dos conceptos, mil prácticas", mus- $A$ № 8, Dirección General de Museos, Consejería de Cultura, Junta de Andalucía, 19-29. 